
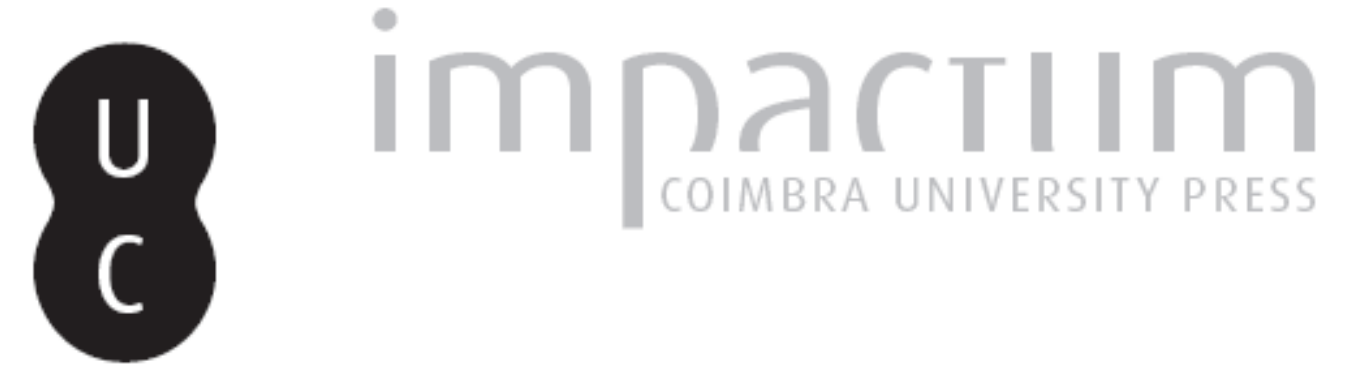

\title{
O tempereiro e a antiguidade do tear horizontal de pedais
}

Autor(es): $\quad$ Alarcão, Adília M.; Ponte, Salete da

Publicado por: Imprensa da Universidade de Coimbra

URL persistente:

URI:http://hdl.handle.net/10316.2/45708

DOI:

DOI:https://dx.doi.org/10.14195/1647-8657_21_7

Accessed : $\quad$ 26-Apr-2023 08:26:53

A navegação consulta e descarregamento dos títulos inseridos nas Bibliotecas Digitais UC Digitalis, UC Pombalina e UC Impactum, pressupõem a aceitação plena e sem reservas dos Termos e Condições de Uso destas Bibliotecas Digitais, disponíveis em https://digitalis.uc.pt/pt-pt/termos.

Conforme exposto nos referidos Termos e Condições de Uso, o descarregamento de títulos de acesso restrito requer uma licença válida de autorização devendo o utilizador aceder ao(s) documento(s) a partir de um endereço de IP da instituição detentora da supramencionada licença.

Ao utilizador é apenas permitido o descarregamento para uso pessoal, pelo que o emprego do(s) título(s) descarregado(s) para outro fim, designadamente comercial, carece de autorização do respetivo autor ou editor da obra.

Na medida em que todas as obras da UC Digitalis se encontram protegidas pelo Código do Direito de Autor e Direitos Conexos e demais legislação aplicável, toda a cópia, parcial ou total, deste documento, nos casos em que é legalmente admitida, deverá conter ou fazer-se acompanhar por este aviso.

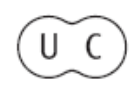


FACULDADE DE LETRAS

INSTITUTO DE ARQUEOLOGIA

\section{CONIMBRIGA}

VOLUMEXXI

UNIVERSIDADE DE COIMBRA

1982 
Adília M. Alarcìo

Directora do Museu Monográfico de Conimbriga

Sálete da Ponte

Conservadora do Museu Monográfico de Conimbriga

O TEMPEREIRO E A ANTIGUIDADE DO TEAR HORIZONTAL DE PEDAIS

Conimbriga, XXI, 1982, p. 163-168

RESUMO: Dá-se a conhecer um tempereiro de madeira com pontas de ferro usado actualmente num tear horizontal de pedais em Condeixa-a-Nova e retoma-se o problema da antiguidade deste tipo de tear. Algumas peças de ferro encontradas em Conimbriga e publicadas, mas sem correcta interpretação, em Fouilles de Conimbriga, VII, parecem demonstrar que o tear horizontal era já conhecido na época romana tardia.

SUMMARY : Several small iron objects found at the site of Conimbriga and published in Fouilles de Conimbriga, VII, have now been properly recognized. They are like the metal tips from the temple - a horizontal ruler-like beam which maintains the width of the cloth uniform - of a warp-weighted horizontal loom still in use at Condeixa at the present day. This similarity seems to indicate that horizontal looms were already in use during the late empire. 
(Página deixada propositadamente em branco) 


\section{O TEMPEREIRO E A ANTIGUIDADE DO TEAR HORIZONTAL DE PEDAIS}

O tempereiro é uma peça usada no tear horizontal de pedais para regular a largura do tecido e mantê-lo sempre esticado à medida que o ño da trama vai passando pelos liços e forma o urdume.

Ilustramos neste artigo um modelo (*) cujo desenho (Est. I), não vimos ainda reproduzido em qualquer publicação ( $\left.{ }^{2}\right)$. Conhecemos, além desta peça, mais 6 exemplares provenientes de Bendafé (Condeixa-a-Nova) ${ }^{(3)}$, feitos de madeira e ferro e não só de ferro forjado como este acessório de tecelagem é habitualmente representado $\left({ }^{4}\right)$.

No exemplar conservado em Condeixa, as varetas são de madeira com secção em D e apresentam as extremidades formadas

(q Este exemplar pertence ao Exmo. Senhor Álvaro Pedro Augusto residente em Condeixa-a-Nova. A peça fazia parte de um tear horizontal de sua avó o qual foi há já alguns anos desmontado, restando poucos acessórios.

(2) Cf. ernesto Veiga de Oliveira, Fernando Galhano, Benjamim Pereira, Tecnologia tradicional Portuguesa. O linho, Lisboa, 1978 (= Veiga DE Oliveira, O linho)] cf. ainda recensão bibliográfica a este volume no número 19, 1980, da revista «Conimbriga».

(3) Agradecemos a Miguel Pessoa, do Museu Monográfico de Conimbriga, por nos ter informado da existência destes exemplares em Bendafé os quais se encontram — segundo supomos — inéditos. A fotografia que reproduzimos é da sua autoria.

$\left({ }^{4}\right)$ Cf. Veiga de Oliveira, $O$ linho, fig. 91; cf. Margarida ribeiro, Contribuição para o Estudo de Teares Manuais, «Revista de Etnografìa», n. ${ }^{\circ}$ 1, Porto, p. 14-15, fig. 11-12.

Conimbriga, 21 (1982), 163-168 
por uma peça de ferro com cabo em alvado e topo espalmado, munido de 3 dentes; cada uma das varetas é atravessada por 3 orifícios que, unidos por um cordão, determinam a maior ou menor largura do tecido. Esta união é reforçada por um anel de ferro. Nos exemplares da Bendafé as varetas são igualmente de madeira, atravessadas por três furos cada e unidos por um cordão durante a execução do trabalho; contudo, observa-se uma diferença curiosa: a secção das varetas é rectangular e estas não funcionam sobrepostas mas sim paralelamente (Est. III). Os terminais destes tempereiros são muito semelhantes e apenas ligeiramente maiores que os dois objectos provenientes de Conimbriga aqui ilustrados e que noutro lugar $\left(^{5}\right)$ classificámos - ainda que com muitas dúvidas - como instrumentos usados pelo estucador na preparação das camadas mais finas de revestimento do estuque. A repartição dos achados um pouco por toda a parte (ruas, criptopòrtico, termas), em estratos remexidos ou pertencentes ao habitat bárbaro não ajudava a interpretação funcional e cronológica de tais instrumentos. Perante os tempereiros do concelho de Condeixa-a-Nova, julgamos não haver dúvida de que os objectos de Conimbriga representados pelo n. 44 (Est. II, n. ${ }^{\circ} 1$ ) são extremidades de objectos idênticos ou pelo menos bastante semelhantes; os restantes exemplares ilustrados pelo n. ${ }^{\circ} 43$ (Est. II, n. ${ }^{\circ}$ 2) apresentam um espigão que exigiria outro tipo de encabamento o qual, à primeira vista, não parece ajustar-se facilmente a uma vareta de tempereiro com as dimensões e formatos até agora registados, sem que tal invalide a possibilidade de terem cumprido a mesma função.

O problema da antiguidade do tempereiro continua em aberto, já que os testemunhos materiais de tear horizontal de pedais referidos por vários autores $\left(^{6}\right)$ são demasiadamente ténues para

(5) A. Moutinho Alarcão e S. da Ponte, Les métiers et leur outillage. Instruments de lissage, de retouchage et de modelage, Fouilles de Conimbriga, VII, Paris, 1979, p. 26, Est. III, 43 e 44.

$\left.{ }^{6}\right)$ Cf. Veiga de Oliveira, O linho, p. 125-126; cf. Marta Hoffmann, The Warp-Weighted Loom, 1964 (= Hoffmann, The Warp-Weighted Loom), p. 333-336; cf. J. P. WILD, Textile Manufacture in the Northern Roman Provinces, Cambridge, 1970 (= Wild, Textile Manufacture), p. 53 e 75-78, 
permitirem situá-lo na época romana. $O$ seu aparecimento na Europa está associado à descrição feita por Alexander Neckam nos fins do séc. xii, pela primeira vez ilustrada numa iluminura do séc. XIII $\left(^{7}\right)$. O tear horizontal de pedais parece ter a sua origem mais remota na China, cujo modelo aparece representado em pedras esculpidas da época Han (206 a.C.-220 d.C.); o uso deste aparelho no mundo romano estará, porventura, associado à importação da seda Han que ocorreu, pelo menos, a partir de 395 d.C. $\left(^{8}\right)$.

A relação entre o citado tear chinês, o modelo que possa ter existido no Baixo Império Romano e o modelo que se impôs na Europa Ocidental em plena Idade Média, talvez não seja uma relação directa. Marta Hoffmann pensa que este último terá vindo do Oriente numa época intermediária relativamente tardia $\left({ }^{9}\right)$.

A descoberta em Conimbriga dos citados acessórios não aduz prova cronológica indiscutível. O n.$^{\circ} 44$ provém de uma camada remexida e dos 11 exemplares idênticos, não ilustrados, 7 possuem a mesma situação, 1 foi encontrado numa canalização das termas flávio-trajânicas e 3 surgiram em níveis de destruição do habitat romano.

O n. ${ }^{\circ} 43$ e outro exemplar igual, não ilustrado, provém da camada de destruição do forum, havendo mais 17 encontrados em camadas remexidas. A destruição do forum e do quarteirão habitacional situado nas suas vizinhanças está relacionada com os ataques suévicos de 465 e 468; no entanto, dada a situação bastante superficial dessa camada não se pode afirmar que todos os objectos nela encontrados são contemporâneos ou anteriores, pois há que admitir a possibilidade de intrusão posteriori ${ }^{10}$ ).

Por outro lado, não é crível que os trabalhos agrícolas desenvolvidos ao longo dos séculos após o completo abandono de Conimbriga como local de habitação, sejam os responsáveis

( ${ }^{7}$ Cf. Veiga de Oliveira, O linho, p. 126, fig. 68; cf. Wild, Textile Manufacture, p. 76.

(8) Cf. Wild, Textile Manufacture, p. 53 e 77.

( ${ }^{9}$ Cf. Hof Fмan, The Warp-Weighted Loom, p. 336.

(10) O significado da camada de destruição de Conimbriga foi objecto de larga discussão em $A$ propos des céramiques de Conimbriga, "Conimbriga», XIV, 1975, p. 79-84. 
pelo aparecimento de 32 objectos tâo semelhantes entre si, numa área relativamente concentrada e num contexto arqueológico onde faltam quase por completo testemunhos de ocupação posterior ao séc. vu ( $\left.{ }^{\mathrm{n}}\right)$.

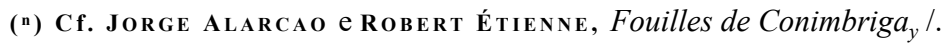
VArchitecture, Paris, 1977, p. 10.

Conimbriga, 21 (1982), 163-168 


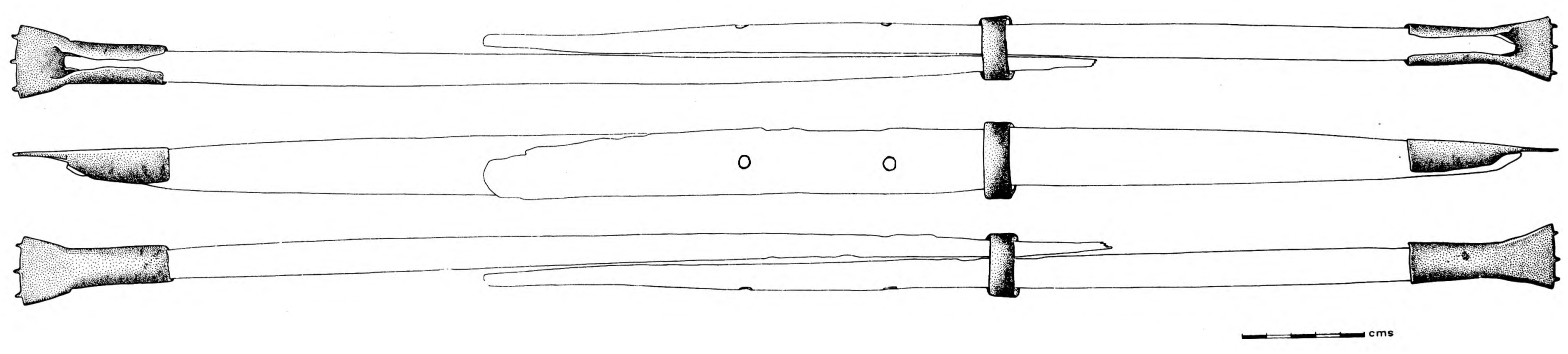




\section{(Página deixada propositadamente em branco)}


EsT. II
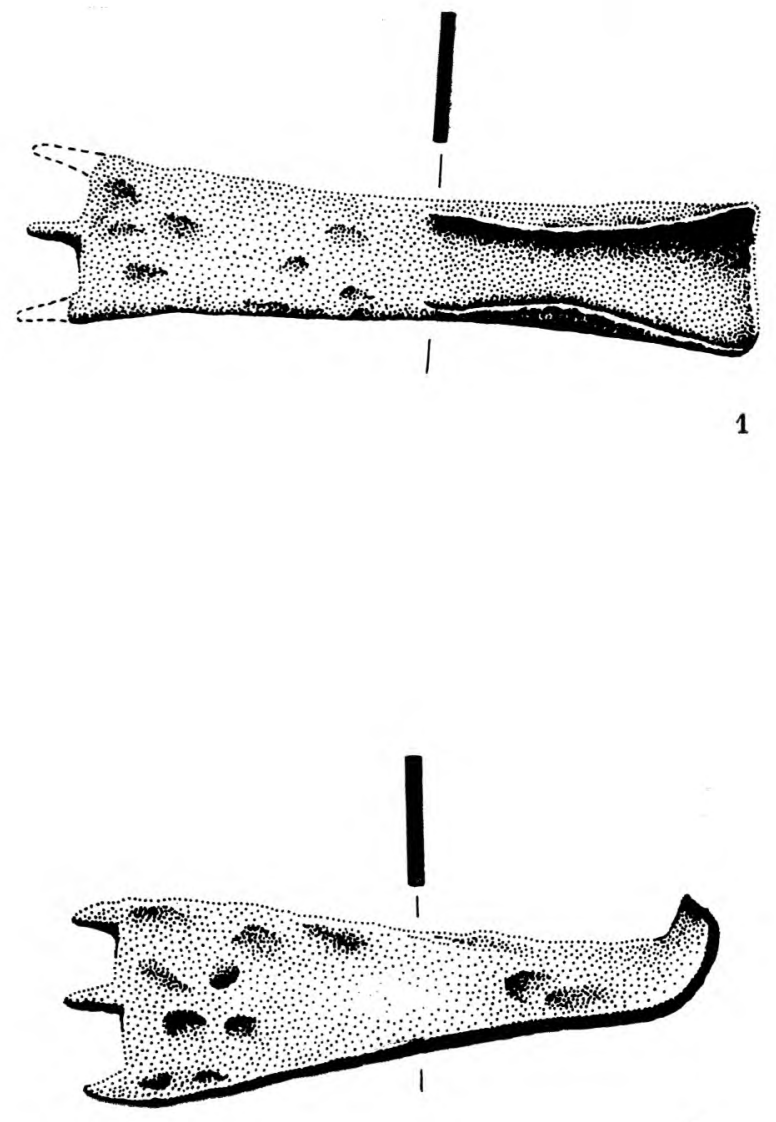

2

Esc. 1:1 


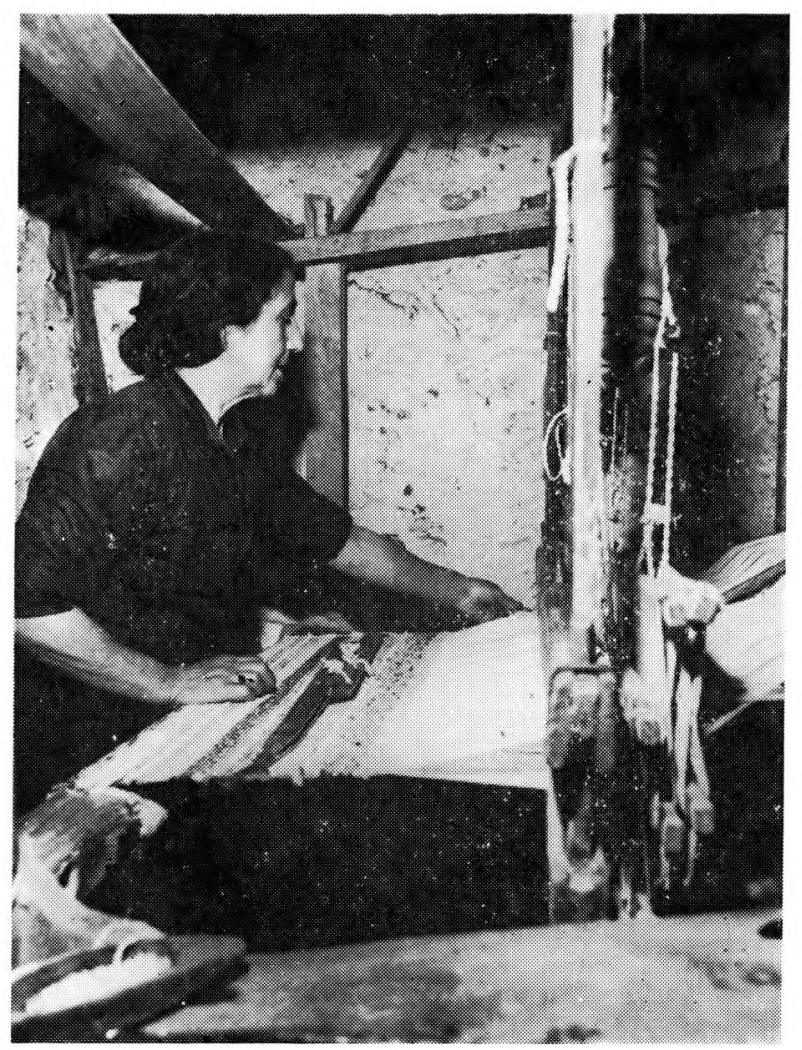

